\title{
Clinicopathological characteristics and treatment of young women with breast cancer in China: a nationwide multicenter 10-year retrospective study
}

\author{
Wei Zhang ${ }^{1 \#}$, Bai-Lin Zhang ${ }^{2 \#}$, Jian-Jun $\mathrm{He}^{1}$, Jin-Hu Fan ${ }^{3}$, Jing $\mathrm{Li}^{4}$, Bin Zhang ${ }^{5}$, Hong-Jian Yang ${ }^{6}$, \\ Xiao-Ming Xie ${ }^{7}$, Zhong-Hua Tang ${ }^{8}$, Hui Li ${ }^{9}$, Jia-Yuan Li ${ }^{10}$, Shu-Lian Wang ${ }^{11}$, You-Lin Qiao ${ }^{3}$, \\ Rong Huang ${ }^{3}$, Pin Zhang ${ }^{12}$
}

${ }^{1}$ Department of Breast Surgery, First Affiliated Hospital of Xi'an Jiaotong University, Xi'an, China; ${ }^{2}$ Department of Breast Cancer, Cancer Institute/ Hospital, Chinese Academy of Medical Sciences \& Peking Union of Medical College, Beijing, China; ${ }^{3}$ Department of Cancer Epidemiology, National Cancer Center/National Clinical Research Center for Cancer/Cancer Hospital, Chinese Academy of Medical Sciences and Peking Union Medical College, Beijing, China; ${ }^{4}$ Department of Occupational and Environmental Health, West China School of Public Health, Sichuan University, Chengdu, China; ${ }^{5}$ Department of Breast Surgery, Liaoning Cancer Hospital, Shenyang, China; ${ }^{6}$ Department of Breast Surgery, Zhejiang Cancer Hospital, Hangzhou, China; ${ }^{7}$ Department of Breast Oncology, Sun Yat-Sen University Cancer Center, Guangzhou, China; ${ }^{8}$ Department of Breastthyroid Surgery, Xiangya Second Hospital, Central South University, Changsha, China; ${ }^{9}$ Department of Breast Surgery, the Second People's Hospital of Sichuan Province, Chengdu, China; ${ }^{10}$ Department of Epidemiology, West China School of Public Health, Sichuan University, Chengdu, China; ${ }^{11}$ Department of Radiotherapy, Cancer Institute \& Hospital, Chinese Academy of Medical Sciences \& Peking Union Medical College, Beijing, China; ${ }^{12}$ Department of Medical Oncology, Cancer Institute \& Hospital, Chinese Academy of Medical Sciences \& Peking Union Medical College, Beijing, China

Contributions: (I) Conception and design: W Zhang, JJ He; (II) Administrative support: W Zhang, JJ He; (III) Provision of study materials or patients: W Zhang, BL Zhang, JJ He, J Li, B Zhang, HJ Yang, XM Xie, ZH Tang, H Li, JY Li, SL Wang, P Zhang; (IV) Collection and assembly of data: Wei Zhang, JJ He; (V) Data analysis and interpretation: R Huang, JH Fan; (VI) Manuscript writing: All authors; (VII) Final approval of manuscript: All authors.

\#These authors contributed equally to this work and shared the first authorship.

Correspondence to: Dr. Jian-Jun He. Department of Breast Surgery, First Affiliated Hospital of Xi'an Jiaotong University, Xi'an, China. Email: chinahjj@163.com; Dr. Jin-Hu Fan. Department of Cancer Epidemiology, National Cancer Center/National Clinical Research Center for Cancer/Cancer Hospital, Chinese Academy of Medical Sciences and Peking Union Medical College, Beijing, China. Email: fanjh@cicams.ac.cn.

Background Breast cancer is currently the most common female malignancy in China. However, the clinical features and overall prognosis of young women diagnosed with this malignancy remain unclear. This study aimed to describe the clinicopathological characteristics of young patients ( $\leq 34$ years of age) with breast cancer and explore the current treatment approaches used in China.

Methods: This was a hospital-based, multicenter, retrospective study of women with breast cancer across seven Chinese hospitals from 1999 to 2008 . A total of 295 young ( $\leq 34$ years of age) patients (research group) and 2,119 women aged 35 to 49 years (control group) were included in the study. Patient epidemiology, preoperative examinations, clinical pathology, and treatment were analyzed.

Results: The percentage of young patients with breast cancer in the study group was $7.01 \%$. These young women had a lower body mass index (BMI), a higher level of education, a lower number of previous births, and a lower history of breastfeeding than the control group $(\mathrm{P}<0.05)$. Increasingly, pre-operative use of ultrasound and magnetic resonance imaging are being used to diagnose breast cancer in young women in China. In young women with breast cancer, breast cancer not otherwise specified (NOS) was the primary pathology. The carcinoma in young women was more prone to lymph node metastasis, showed less progesterone receptor (PR) expression, and was more advanced than observed in the control group $(\mathrm{P}<0.05)$. We found that the number of young breast cancer patients undergoing breast-conserving surgery in China is increasing.

Conclusions: Young breast cancer patients display unique clinicopathological features, including tumors of a higher grade than those aged 35 years or older. As breast cancer is more aggressive in younger women, 
prevention and early diagnosis are critical, and new policies should be developed in line with these findings.

Koywords: Young age; breast cancer; clinicopathological characteristics; retrospective study

Submitted Jun 21, 2020. Accepted for publication Nov 13, 2020.

doi: $10.21037 /$ gs-20-574

View this article at: http://dx.doi.org/10.21037/gs-20-574

\section{Introduction}

Breast cancer in young women has a low incidence, ranging from $6 \%$ to $25 \%$, depending on the geographical location (1-10). Developing breast cancer at a young age is considered an independent and adverse prognostic factor $(5,10-20)$. Up to $15-30 \%$ of very young patients with breast cancer ( $\leq 34$ years old) are likely to have BRCA1 and BRCA2 germline mutations (21-23). These germline mutations are associated with high-risk prognostic factors, including lack of estrogen receptors (ER), higher histological grade, and high proliferation rate.

However, the prognosis of young patients with breast cancer remains controversial. Two population-based studies previously examined the relationship between age and risk of death and found a higher risk of death in young patients diagnosed with breast cancer compared with older patients $(16,18)$. However, other studies have shown that there was no impact of age on overall survival and disease-free survival in women with breast cancer $(24,25)$. In addition, some studies even point to the fact that young patients with breast cancer have a better prognosis $(26,27)$.

These differences in prognoses may reflect differences in the treatment choices made by younger women with breast cancer. As young patients tend to be more concerned by the appearance and fertility challenges resulting from some breast cancer treatments, and are more vulnerable to social and psychological pressures, their treatment choice may differ compared with older patients. For example, it has been previously reported that in women of reproductive age, fertility issues due to treatment for breast cancer is a significant concern (28).

In China, even though breast cancer is currently the most common malignancy, the characteristics of very young breast cancer patients ( $\leq 34$ years of age) remain unclear. We defined the age of less than 35 as the definition for very young patients according to several previous studies $(2,4,9,29)$ and clinical experience. The objective of the current study was to explore the clinicopathological features of very young patients with breast cancer in China, and their treatment choice compared to older patients with breast cancer ( $\geq 35$ years old). We present the following article in accordance with the STROBE reporting checklist (available at http://dx.doi.org/10.21037/gs-20-574).

\section{Methods}

\section{Study design and quality control}

This study was a hospital-based, multicenter, retrospective study of female primary breast cancer cases that was approved by the Cancer Foundation of China Institutional Review Board (Approval: XJTU1AF2020LSK-211). The study was conducted in accordance with the Declaration of Helsinki (as revised in 2013). We analyzed data from breast cancer patients over a period of 10 years, from 1999 to 2008.

Patient consent was not required, as there were no anticipated risks for the participants. However, all patient information was kept confidential, with all data stripped of any patient identifiers. The clinical and pathological characteristics of premenopausal women diagnosed with breast cancer were collected.

Mainland China is divided into seven regions. One hospital with the highest level of breast cancer diagnosis and treatment was selected from each of the seven regions (i.e., north, northeast, northwest, central, east, south, and southwest China). Each individual hospital was responsible for the comprehensive diagnosis and appropriate treatment choice.

All patients enrolled in this study met the following inclusion criteria: (I) they have pathology confirmed primary breast cancer; (II) their admission date was within the selected month chosen by the study hospital; (III) they had received or were currently receiving treatment for breast cancer. Each hospital collected data from more than 50 cases per month during 1999-2008. Therefore, each hospital provided records for more than 500 cases over ten years.

In total, data from 4,211 cases were collected, including 


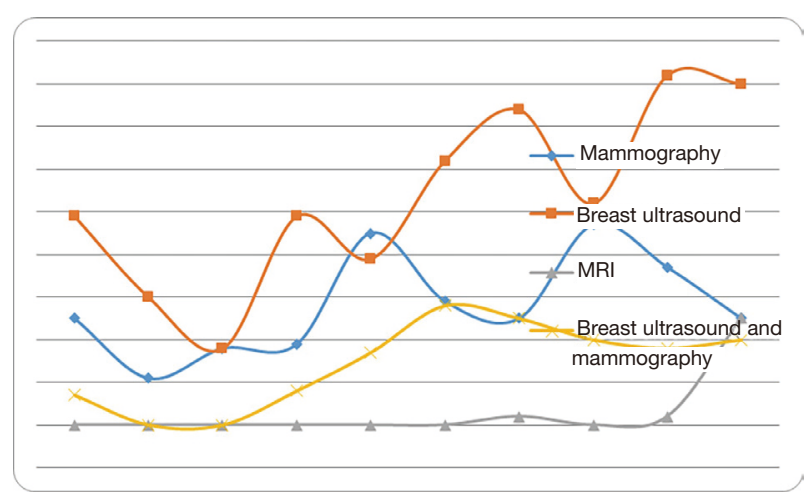

Figure 1 The percentage of young ( $\leq 34$ years old) women diagnosed with breast cancer compared to all women diagnosed with breast cancer per year over a 10-year period (1999 to 2008).

295 cases of young women ( $\leq 34$ years of age) that were diagnosed with breast cancer (research group). Data were collected using two independent inputting operators, and all data underwent qualification control. The regional data was validated with the EpiData software described previously in detail by Li et al. (1).

\section{Data collection and stratification}

The primary medical information was extracted, including general information, risk factors, imaging diagnosis, pathological features, and treatment. The histological subtype was determined using the 1981 and 2003 World Health Organization (WHO) histological classification criterion. The staging of breast cancer was determined using the 1997 American Joint Committee on Cancer (AJCC) Tumor Node Metastasis (TNM) stage criterion.

The expression of ER, progesterone receptor (PR), and human epidermal growth factor receptor-2 (HER2) were detected by immunohistochemistry using ER, PR, and HER2-specific antibodies. ER, PR, and HER2 results were obtained from the medical records. A HER2 score of 3+ was considered HER2 positive (HER2+), whereas a HER2 score of $0,1+$, or $2+$ was considered HER2 negative (HER2-).

\section{Statistical analysis and comparison of multiple group data}

Comparison of the epidemiology, pre-operative examinations, clinical pathology, and treatment between the control group and the research group were analyzed. The chi-square test was used to analyze the epidemiology, preoperative examination, clinical pathology, and treatment status data in the control and research groups. The chisquare test was used to examine pre-operative imaging, clinical-pathological characteristics, and treatment trends over ten years. All statistics were analyzed with the Statistical Package for the Social Sciences (SPSS, version 17.0). A $\mathrm{P}$ value of $<0.05$ was considered statistically significant.

\section{Results}

From a total of 2,414 examined cases during 1999-2008, there were 2,119 cases of women aged 35 to 49 with primary breast cancer (control group) and 295 cases of young women ( $\leq 34$ years of age) with breast cancer (research group).

\section{Incidence of young women with breast cancer}

The percentage of young women $(\leq 34$ years of age) diagnosed with breast cancer was less than $10 \%$ per year over ten years, and this incidence did not vary significantly over time (Figure 1). Overall, the research group ( $\leq 34 \mathrm{y}$, $\mathrm{n}=295)$ represented only $7.01 \%(295 / 4,211)$ of all breast cancer patients studied. The mean age was 30.9 years and 43.5 years in the experimental group and control group, respectively.

\section{Epidemiology of young women with breast cancer}

The majority (78.43\%) of young breast cancer patients were with normal body mass index (BMI) in the experimental group. The mean BMI of women in the experimental group (21.09) was lower than that in the control group (22.68; $\mathrm{P}<0.001)$. A higher proportion of women with a low BMI $(\leq 18)$ were found in the experimental group compared with the control group $(11.8 \%$ vs. $4.13 \%$, respectively; $\mathrm{P}<0.001)$.

In both the research group and the control group, there were more women whose occupation was more manual labor (manual worker) rather than knowledgebased labor (mental worker). More women had finished higher education $(58.2 \%)$ in the experimental group than women in the control group (43.0\%). Most women of the experimental group had only one child $(72.5 \%)$, while $63.3 \%$ of women aged over 35 had only given birth to one child. A higher percentage of the patients in the control group had a history of breastfeeding $(90.2 \%)$ compared to the experimental group (77\%). Table 1 contains the clinical baseline characteristics for all patients. 
Table 1 Comparison of clinical characteristics between breast cancer patients in the research group ( $\leq 34$ years old) and the control group (35-49 years old)

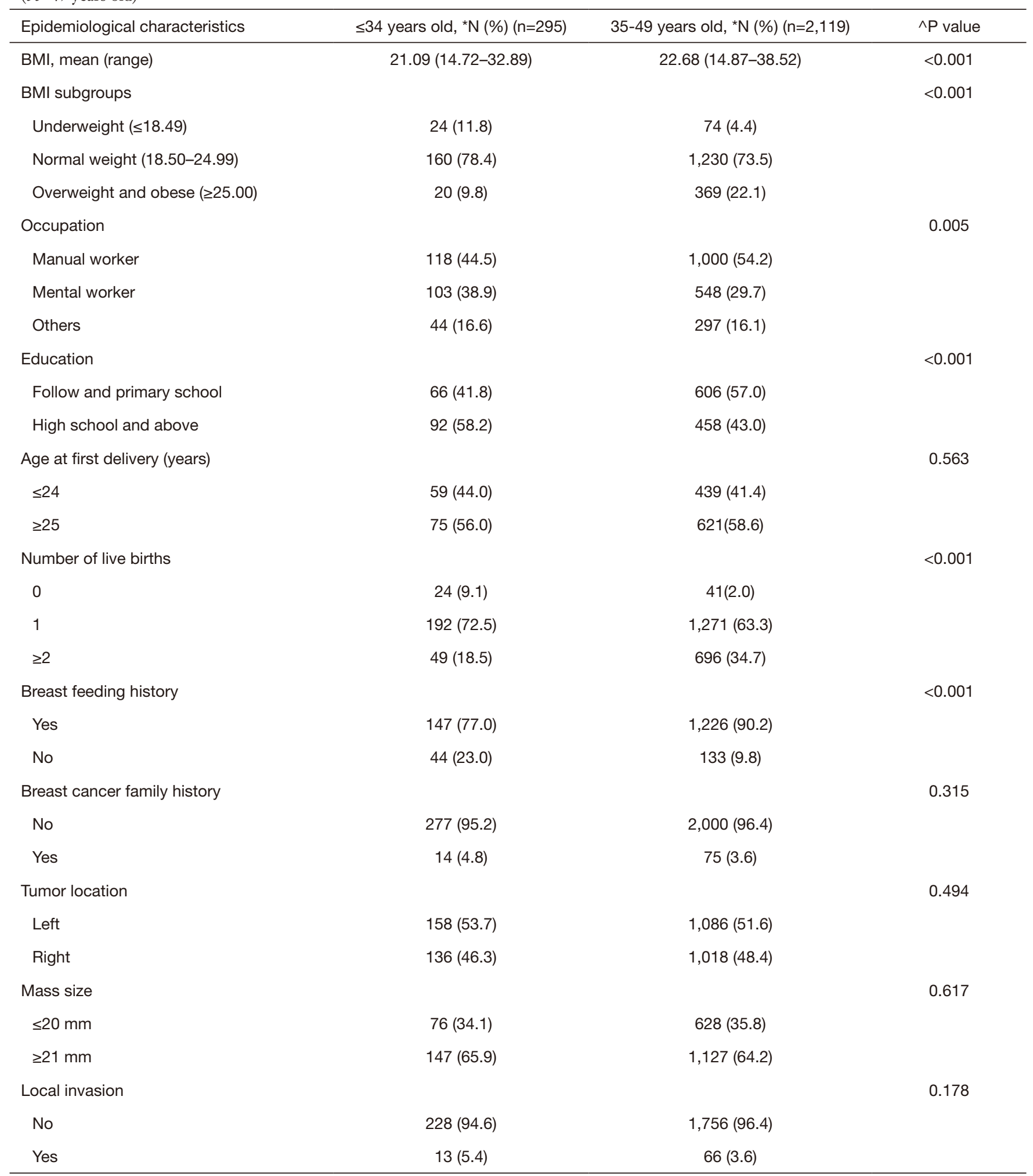

Table 1 (continued) 
Table 1 (continued)

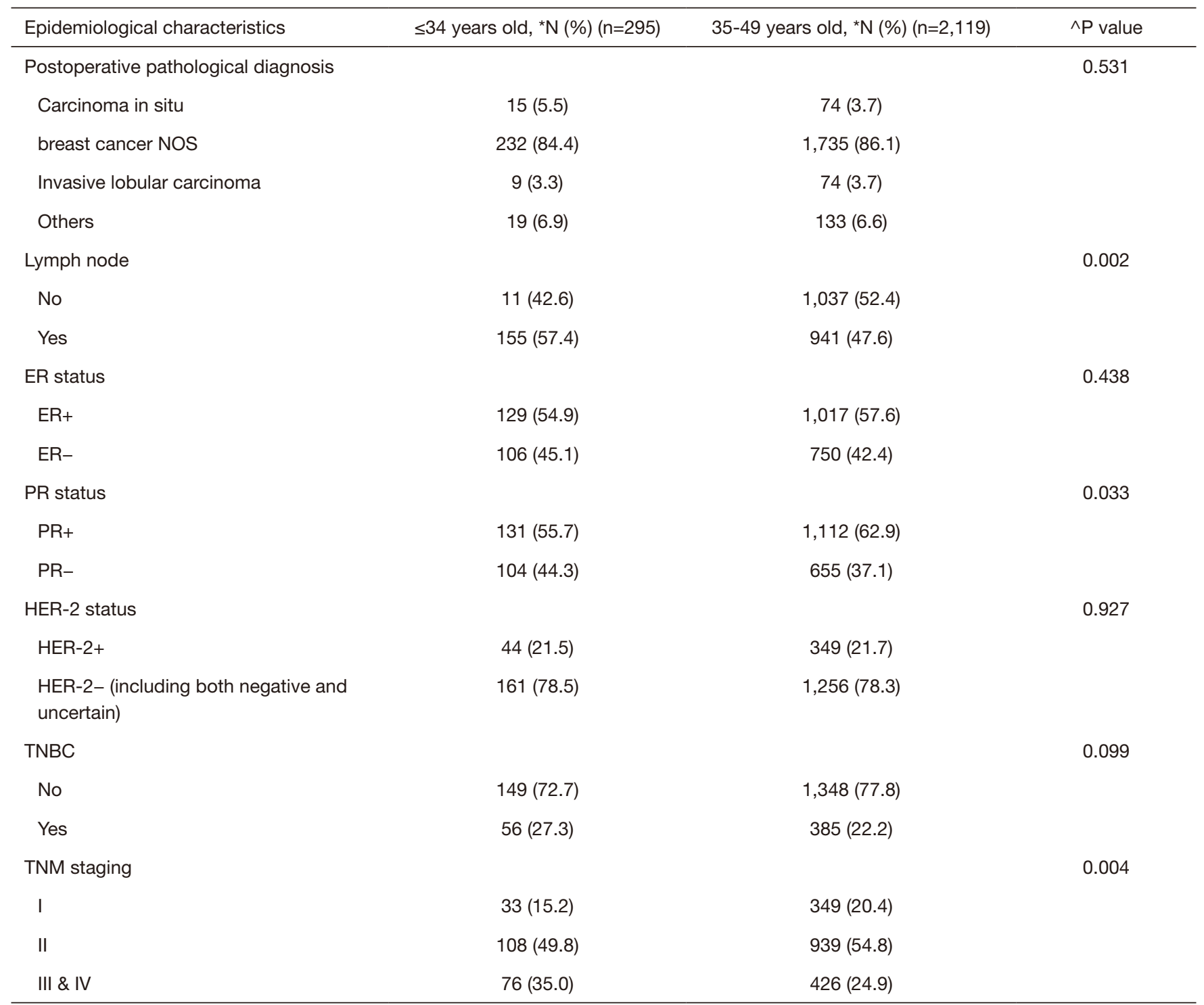

*, or specified; ^, Chi-square test. Missing data in some of the following categories. NOS, not otherwise specified; BMI, body mass index; N, patient number of each subgroup; $n$, sampling size; ER estrogen receptor; PR progestogen receptor; TNBC triple negative breast cancer; HER-2, human epidermal growth factor receptor 2; TNM, tumor size, lymph nodes, and metastases.

\section{Preoperative imaging techniques used in young women}

Imaging techniques are commonly used to diagnose breast cancer. We examined any trends between the type of preoperative imaging examination used for young women under 35 years of age with young breast cancer over time. We divided the ten years into two stages, namely 1999-2003 and 2004-2008. We found that pre-operative breast ultrasound and MRI use is becoming significantly more frequent $(\mathrm{P}<0.001)$ in recent years compared with mammography (Table 2, Figure 2).

\section{The difference in breast cancer pathology}

We examined the main clinical pathology found in women below 35 years of age compared to the control group (Table 1). Infiltrating ductal carcinoma was the main postoperative pathology in these women and was found in $84.4 \%$ of our research group (Table 1). Compared with 
Table 2 Diagnostic examination and treatment allocation in the research group of young patients ( $\leq 34$ years old)

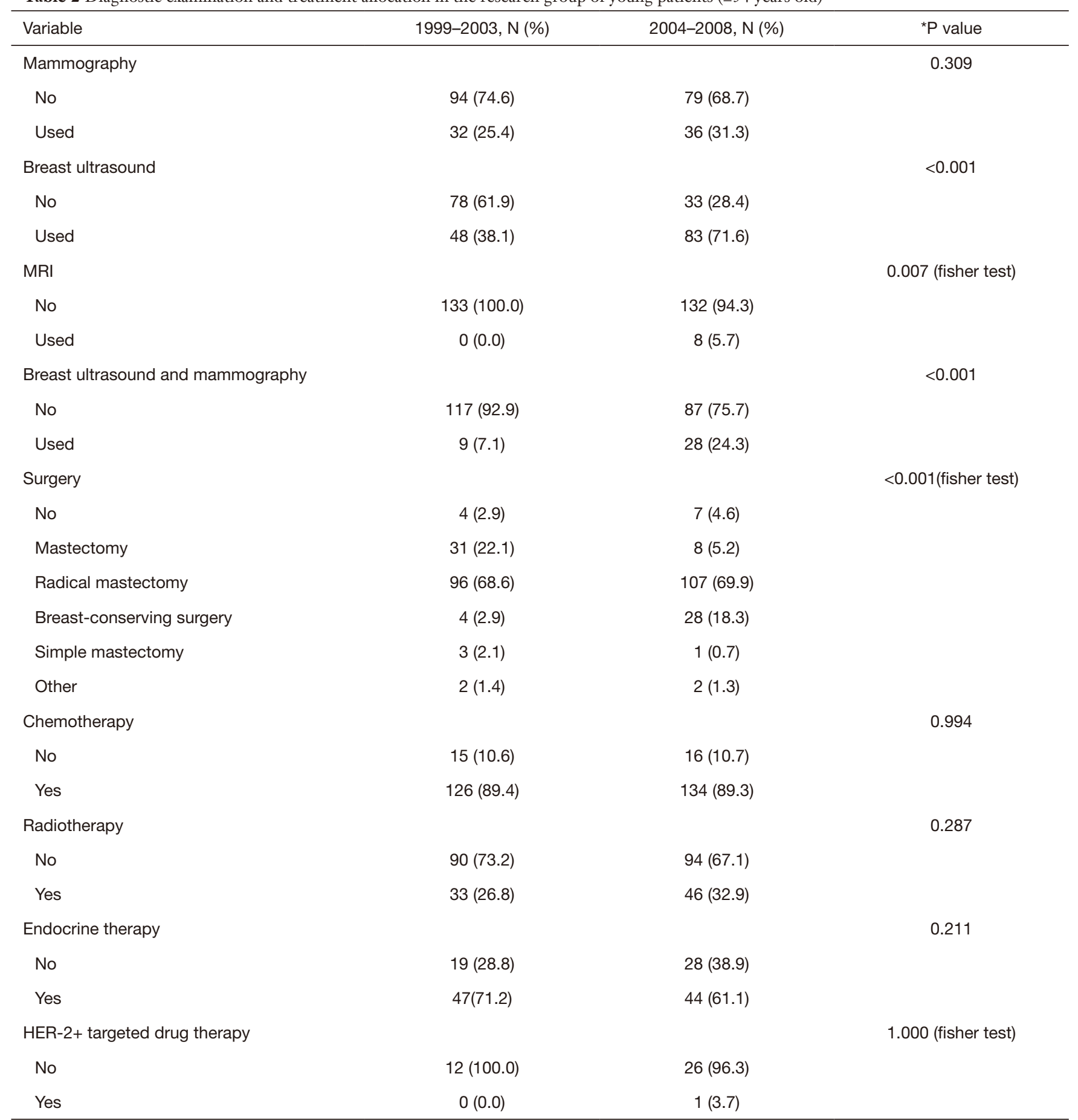

*, chi-square test or specified. N, patient number of each subgroup; n, sampling size; MRI, magnetic resonance imaging; HER-2, human epidermal growth factor receptor 2 . 


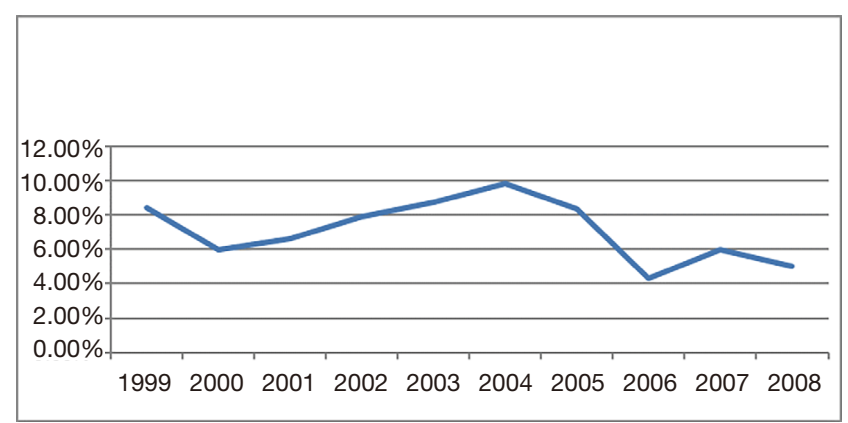

Figure 2 The use of different types of preoperative diagnostic imaging in young women ( $\leq 34$ years old) diagnosed with breast cancer (research group) over time. Breast ultrasound and MRI is used more frequently in recent years, whereas the use of mammography and combined ultrasound/mammography has remained more consistent.

patients of the control group, women in the research group presented significantly more lymph node metastasis $(57.4 \%$ vs. 47.6\%; $\mathrm{P}=0.002)$, less $\mathrm{PR}$ expression (55.7\% vs. 62.9\%; $\mathrm{P}=0.033)$, and were in the more advanced tumor stages (stages III \& IV: $35.0 \%$ vs. $24.9 \%$; $\mathrm{P}=0.04$ ) based on the AJCC Cancer Staging Manual (30). However, there were no statistically significant differences in the number of other pathological characteristics, including tumor location, tumor size, local invasion, pathological type, ER expression, and HER2 status $(\mathrm{P}>0.05)$.

\section{Treatment choices in young women with breast cancer}

The majority (96.3\%) of young patients had operative resection of their breast tumors, with $70.9 \%$ undergoing modified radical mastectomy (Table 2). In contrast, only $10.9 \%$ of patients chose to have breast-conserving surgery. However, over time, we found that the number of patients who underwent breast-conserving surgery increased $(2.9 \%$ in $1999-2003$ vs. $18.3 \%$ in 2004-2008), while the number of patients choosing radical mastectomy gradually reduced over time $(22.1 \%$ in $1999-2003$ vs. $5.2 \%$ in $2004-2008)$. Such differences were statistically significant $(\mathrm{P}<0.05)$. However, we found no statistically significant differences between radiation therapy, hormone replacement therapy, or targeted drug therapy over time $(\mathrm{P}>0.05)$.

\section{Discussion}

While breast cancer diagnosis under 35 is relatively uncommon, it is considered a separate prognostic factor $(5,10-20)$. In this retrospective study spanning ten years, we examined the clinicopathological characteristics of young women with breast cancer from all over China, confirming that women's age is a unique prognostic factor.

In this study, $7.01 \%$ of the patients with breast cancer were less than 35 years of age at diagnosis. This incidence rate agrees with reports from other Chinese research centers $(3,13)$ and other countries $(2,5,6,9)$. However, it is lower than other research reports from Asia, which report an incidence of $10 \%$ to $25 \%(8,31)$, and is lower than that reported in the Western world $(4,10)$. There are several reasons to explain the variation in the observed prevalence rates between our study and others. First, there may be a genetic predisposition to breast cancer found in some populations. Additionally, there may be different levels of medical resources available in different countries, and there may be lack of a national breast cancer detection system. Finally, there could be sampling errors due to the methods of data collection.

Our study found that breast cancer patients less than 35 years of age showed a lower BMI than those over 35 years. Further, a higher proportion of these women had completed higher education, had an occupation that required mental labor, had more single births, and a lower number had previously breastfed compared to the control group $(\mathrm{P}<0.05)$. Our findings are consistent with other reports in the literature (32-34). We suggest that young women engaged in an occupation requiring more mental labor are exposed to more risk factors for developing breast cancer, such as the pressure from work and society. Due to their young age, they may also pay more attention to their image and controlling their weight, which would explain their low BMI compared to the control group.

These women engaged in an occupation requiring more mental labor have spent a long time completing their education and professional development, resulting in older age for their first child's delivery. This would explain the lower number of live births and a lower history of breastfeeding. In the present study, there were statistically significant differences between the two groups in the number of births and history of breastfeeding. According to the available evidence, women who have fewer children and are not breastfeeding have a higher risk of breast cancer. It was reported that each full-term pregnancy can reduce the risk of breast cancer in premenopausal women by $3 \%$, and increasing the number of pregnancies can also reduce the risk of breast cancer (35). In addition, for 
both premenopausal and postmenopausal women, every 12 months of lactation has been shown to reduce breast cancer risk by $4.3 \%$ (36). These findings encourage us to add relevant content to health education in breast cancer prevention.

Imaging examination is commonly used to diagnose breast cancer. Due to the higher density of mammary glands and gland nodules in young women, conventional medical exam accuracy for diagnosing breast cancer is reduced $(29,37)$. For example, in previously published reports, regular physical examination was only $37 \%$ accurate for diagnosing breast cancer in young women (37). We observed significant changes in the types of imaging diagnostic examinations performed between the two time periods of 1999-2003 and 2004-2008. It is important to note that China's available resources for the early detection of breast cancer have changed over time. Since 2004, the Chinese government has gradually changed medical insurance policy, and more patients can now see a doctor in the hospital, which may explain some of the changes observed in our study. We found that breast ultrasound and MRI for breast cancer diagnosis are significantly increasing over time. However, the number of cases using MRI is still relatively low, which may be explained by this technique's higher cost.

Pathological characteristics are related to therapy and prognosis for many diseases. In our study, women under 35 years of age had more lymph node metastasis, lower PR expression, and more advanced disease stages than older women. Our results are similar to those of previously published research in China and other Asian countries $(3,13,29)$. Therefore, as supported by previous studies, younger women appear to have a more aggressive breast cancer with a worse prognosis $(2,4,11,16,20,38-40)$. As the mammary glands of younger women have a higher density, it is not easy for the tumor to be found using regular physical examination and/or mammograms. This leads to the delayed diagnosis of breast cancer in young women, and therefore, a higher probability of metastasis. Notably, although the study group presented more aggressive tumor features, there was no difference in the application of chemotherapy across groups. The finding reflected that the treatment for patients with breast cancer during 1999 to 2008 was not consistent among different hospitals in China. These findings suggest that very young patients may need more individualized treatment that reflects their disease state.

ER-positive breast cancers have a better prognosis because they respond favorably to endocrine therapy, whereas HER2 positive cancers are more invasive than HER2 negative cancers. We found no significant differences between the number of HER2 and ER-positive cancers found in young women compared with controls. In our study, $54.9 \%$ of patients were ER-positive, and $21.5 \%$ were HER-2 positive. These are similar rates to previously published results (32). On the other hand, we found a lower incidence of triple-negative breast cancer in young women compared with other reports. Only $27.3 \%$ of young women were diagnosed with triple-negative breast cancer in our study, which is lower than previously found in other countries (2). There is currently no endocrine or targeted drug therapy for triple-negative breast cancer, and therefore, this type of cancer has a poor prognosis (41).

Surgery was the most common treatment in Chinese female breast cancer patients. We found similar numbers of women undergoing surgery, radiotherapy, and endocrine therapy compared to other studies; however, the number of women undergoing chemotherapy in our study was lower than previously reported (13). We further analyzed the surgical methods and found that breast-conserving surgery was increasing yearly. However, the proportion of women choosing breast-conserving surgery was still lower compared to studies from other countries (6). These country-related differences may be due to an increased understanding of the disease by physicians, the patient's personal choice to improve their quality of life, and economic considerations. In clinical practice, the health providers should restrictedly following the indications for the conserving surgery to guarantee a good prognosis while at the same time paying more attention to the patients' concerns to increase their mental health and quality of life.

As there is a difference in breast cancer pathology in younger patients, new treatment methods for these women are required. We also need to consider whether long-acting, more potent treatments are most appropriate for young women. For example, chemotherapy and endocrine therapy may influence fertility in these women. Thewes et al. confirmed that more than half of patients treated for breast cancer have fertility issues (42). Some young patients have expressed concern about their fertility and the possibility of early menopause due to treatment. Therefore, we advise that doctors provide more information to these women when deciding on treatment options for breast cancer.

There are some potential limitations to the conclusions from this study. We selected patients from the highestlevel hospitals in each region. There may be selection bias 
in the cluster of breast cancer patients in these selected hospitals. However, these hospitals were able to maintain a complete clinicopathological record of patients, and most importantly, to ensure national standards for quality control of laboratory tests. These hospitals are also capable of comprehensive cancer treatment. Next, BRCA mutation information is important to explain the poor prognosis of very young women with breast cancer. However, during the study period [1999-2008], the BRCA mutation test was not a routine test in China. Therefore, BRCA data is not present in the current study. Finally, during the study period, most hospitals involved in the study had no tumor grade for breast cancer, while only a few hospitals had incomplete tumor grading records. This caused an information bias for the present study by missing data.

\section{Conclusions}

In Chinese women, breast cancer in young women has unique pathological features and clinical behaviors and tends to be more aggressive. Early detection is critical for patient prognosis, and the increasing use of MRI and breast ultrasound may lead to early diagnosis of breast cancer in young women. Based on the characteristics of young patients with breast cancer reported in this study, the government should make additional policies to guide young women in their breast cancer treatment choices.

\section{Acknowledgments}

Funding: The present study was supported by the Natural science Basic Research Program of Shanxi (Program No. 2020JM-393). We thank the Cancer Institute of the Chinese Academy of Medical Sciences (CICAMS) for providing their expertise in the development of this study. We also thank the local investigators from Beijing, Liaoning (Shenyang), Hunan (Changsha), Guangdong (Guangzhou), Zhejiang (Hangzhou), Shaanxi (Xian), and Sichuan (Chengdu) for data collection and assisting us with completing this project successfully.

\section{Footnote}

Reporting Checklist: The authors have completed the STROBE reporting checklist. Available at http://dx.doi. org/10.21037/gs-20-574

Data Sharing Statement: Available at http://dx.doi. org/10.21037/gs-20-574

Peer Review File: Available at http://dx.doi.org/10.21037/gs20-574

Conflicts of Interest: All authors have completed the ICMJE uniform disclosure form (available at http://dx.doi. org/10.21037/gs-20-574). The authors have no conflicts of interest to declare.

Ethical Statement: The authors are accountable for all aspects of the work in ensuring that questions related to the accuracy or integrity of any part of the work are appropriately investigated and resolved. The study was conducted in accordance with the Declaration of Helsinki (as revised in 2013). The study was approved by the Ethics Committee of the Cancer Foundation of China Institutional Review Board (approval\#: XJTU1AF2020LSK-211). Given the anonymous characteristic and retrospective design the written informed consent from each patient was waived.

Open Access Statement: This is an Open Access article distributed in accordance with the Creative Commons Attribution-NonCommercial-NoDerivs 4.0 International License (CC BY-NC-ND 4.0), which permits the noncommercial replication and distribution of the article with the strict proviso that no changes or edits are made and the original work is properly cited (including links to both the formal publication through the relevant DOI and the license). See: https://creativecommons.org/licenses/by-nc-nd/4.0/.

\section{References}

1. Li J, Zhang BN, Fan JH, et al. A nation-wide multicenter 10-year (1999-2008) retrospective clinical epidemiological study of female breast cancer in China. BMC Cancer 2011;11:364.

2. Desiris K, Dragoumis D, Assimaki A, et al. 51 Very Young Women (<35 Years) with Primary Breast Cancer. a Single Institution Retrospective Analysis (2005-2009). Eur J Cancer 2012;48:S55.

3. Han JG, Jiang YD, Zhang CH, et al. Clinicopathologic characteristics and prognosis of young patients with breast cancer. Breast 2011;20:370-2.

4. Colleoni M, Rotmensz N, Robertson C, et al. Very young women ( $<35$ years) with operable breast cancer: features of disease at presentation. Ann Oncol 2002;13:273-9.

5. El Saghir NS, Seoud M, Khalil MK, et al. Effects of young 
age at presentation on survival in breast cancer. BMC

Cancer 2006;6:194.

6. Dubsky PC, Gnant MF, Taucher S, et al. Young age as an independent adverse prognostic factor in premenopausal patients with breast cancer. Clin Breast Cancer 2002;3:65-72.

7. Surveillance, Epidemiology, and End Results (SEER) Program Public-Use CDROM (1973-1997). National Cancer Institute, DCCPS, Cancer Surveillance Research Program, Cancer Statistics Branch, released April 2000, based on the August 1999 submission.

8. Agarwal G, Pradeep P, Aggarwal V, et al. Spectrum of breast cancer in Asian women. World J Surg 2007;31:1031-40.

9. Kim EK, Noh WC, Han W, et al. Prognostic significance of young age (<35 years) by subtype based on ER, PR, and HER2 status in breast cancer: a nationwide registry-based study. World J Surg 2011;35:1244-53.

10. Han W, Kim SW, Park IA, et al. Young age: an independent risk factor for disease-free survival in women with operable breast cancer. BMC Cancer 2004;4:82.

11. Shannon C, Smith IE. Breast cancer in adolescents and young women. Eur J Cancer 2003;39:2632-42.

12. Kim Y, Choi D, Huh S, et al. 5197 POSTER Prognostic Value of Age at Diagnosis is Prognostic Factors in Young Women With Breast Cancer in Korea. Eur J Cancer 2011:S389.

13. Peng R, Wang S, Shi Y, et al. Patients 35 years old or younger with operable breast cancer are more at risk for relapse and survival: a retrospective matched case-control study. The Breast 2011;20:568-73.

14. Kheirelseid EH, Boggs JM, Curran C, et al. Younger age as a prognostic indicator in breast cancer: a cohort study. BMC Cancer 2011;11:383.

15. Kim IK, Park S, Hwang H, et al. Clinical significance of age at the time of diagnosis among young breast cancer patients. J Breast Cancer 2011;14:314-21.

16. Chung M, Chang HR, Bland KI, et al. Younger women with breast carcinoma have a poorer prognosis than older women. Cancer 1996;77:97-103.

17. Kroman N, Tutt A, Jensen MB, et al. Factors influencing the effect of age on prognosis in breast cancer: population based studyCommentary: much still to learn about relations between tumour biology, prognosis, and treatment outcome in early breast cancer. BMJ 2000;320:474-8.

18. Adami HO, Malker B, Holmberg L, et al. The relation between survival and age at diagnosis in breast cancer. $\mathrm{N}$
Engl J Med 1986;315:559-63.

19. Albain KS, Allred DC, Clark GM. Breast cancer outcome and predictors of outcome: are there age differentials? J Natl Cancer Inst Monogr 1994:35-42.

20. de la Rochefordiere A, Asselain B, Campana F, et al. Age as prognostic factor in premenopausal breast carcinoma. Lancet 1993;341:1039-43.

21. Turchetti D, Cortesi L, Federico M, et al. BRCA1 mutations and clinicopathological features in a sample of Italian women with early-onset breast cancer. Eur J Cancer 2000;36:2083-9.

22. de Sanjosé S, Léoné M, Bérez V, et al. Prevalence of BRCA1 and BRCA2 germline mutations in young breast cancer patients: a population-based study. Int J Cancer 2003;106:588-93.

23. Bakkach J, Mansouri M, Derkaoui T, et al. Contribution of BRCA1 and BRCA2 germline mutations to early onset breast cancer: a series from north of Morocco. BMC Cancer 2020;20:859.

24. Barchielli A, Balzi D. Age at diagnosis, extent of disease and breast cancer survival: a population-based study in Florence, Italy. Tumori 2000;86:119-23.

25. Crowe JP, Jr., Gordon NH, Shenk RR, et al. Age does not predict breast cancer outcome. Arch Surg 1994;129:483-7; discussion 487-8.

26. Chia KS, Du WB, Sankaranarayanan R, et al. Do younger female breast cancer patients have a poorer prognosis? Results from a population-based survival analysis. Int J Cancer 2004; 108:761-5.

27. La Rosa F, Patavino VM, Epifani AC, et al. Ten-year survival and age at diagnosis of women with breast cancer from a population-based study in Umbria, Italy. Tumori 1996;82:441-3.

28. Howard-Anderson J, Ganz PA, Bower JE, et al. Quality of life, fertility concerns, and behavioral health outcomes in younger breast cancer survivors: a systematic review. J Natl Cancer Inst 2012;104:386-405.

29. Brand IR, Sapherson DA, Brown TS. Breast imaging in women under 35 with symptomatic breast disease. Br J Radiol 1993;66:394-7.

30. Edge SB, Byrd DR, Carducci MA, et al. AJCC cancer staging manual. New York: Springer, 2010.

31. Lim SE, Back M, Quek E, et al. Clinical observations from a breast cancer registry in Asian women. World J Surg 2007;31:1387-92.

32. Caid N, Dahmani R, Hasnaoui D, et al. Clinical characteristics of breast cancer in young patients. Eur J Cancer 2011;47:S387. 
33. Ghiasvand R, Maram ES, Tahmasebi S, et al. Risk factors for breast cancer among young women in southern Iran. Int J Cancer 2011;129:1443-9.

34. Pike MC, Henderson B, Casagrande J, et al. Oral contraceptive use and early abortion as risk factors for breast cancer in young women. Br J Cancer 1981;43:72-6.

35. Clavel-Chapelon F, Gerber M. Reproductive factors and breast cancer risk. Do they differ according to age at diagnosis? Breast Cancer Res Treat 2002;72:107-15.

36. Breast cancer and breastfeeding: collaborative reanalysis of individual data from 47 epidemiological studies in 30 countries, including 50302 women with breast cancer and 96973 women without the disease. Lancet 2002;360:187-95.

37. Ashley S, Royle G, Corder A, et al. Clinical, radiological and cytological diagnosis of breast cancer in young women. Br J Surg 1989;76:835-7.

38. Khouchani M, Elomrani A, Mharech A, et al. 5031

Cite this article as: Zhang W, Zhang BL, He JJ, Fan JH, Li J, Zhang B, Yang HJ, Xie XM, Tang ZH, Li H, Li JY, Wang SL, Qiao YL, Huang R, Zhang P. Clinicopathological characteristics and treatment of young women with breast cancer in China: a nationwide multicenter 10-year retrospective study. Gland Surg 2021;10(1):175-185. doi: 10.21037/gs-20-574
POSTER Breast Cancer in Young Woman in South of Morocco. Eur J Cancer 2011;47:S340.

39. Shavers VL, Harlan LC, Stevens JL. Racial/ethnic variation in clinical presentation, treatment, and survival among breast cancer patients under age 35. Cancer 2003;97:134-47.

40. Yao S, Xu B, Ma F, et al. Breast cancer in women younger than 25: clinicopathological features and prognostic factors. Ann Oncol 2009;20:387-9.

41. Spitale A, Mazzola P, Soldini D, et al. Breast cancer classification according to immunohistochemical markers: clinicopathologic features and short-term survival analysis in a population-based study from the South of Switzerland. Ann Oncol 2009;20:628-35.

42. Thewes B, Meiser B, Taylor A, et al. Fertility-and menopause-related information needs of younger women with a diagnosis of early breast cancer. J Clin Oncol 2005;23:5155-65. 